\title{
School Bullying, Perpetration, and Cyberhate: Overlapping Issues
}

\author{
Catherine Blaya $^{1,2} \cdot$ Catherine Audrin $^{1,3}$ (D) Grace Skrzypiec $^{4}$
}

Published online: 4 September 2020

(C) The Author(s) 2020

\begin{abstract}
In an international context of increasing racism, xenophobia, anti-Semitism, and Islamophobia in Europe and the USA (FRA, 2013; Hawdon et al. 2015), social media provide a privileged tool for propaganda and victimization. Issues of racism and xenophobia have become more prevalent both in "real life" and on the Internet. This study presents the results of a selfreported questionnaire survey on cyberhate among 1900 French students, age 12-20, where we investigated the association between school bullying and cyberhate victimization and perpetration. Findings show that bullying and cyberhate are a common experience for quite a few young people. Structural equation models provide evidence of the association between ordinary offline victimization and involvement in cyberhate. Our findings for cyberhate provide further evidence suggesting an overlap between traditional bullying and cyberbullying. They confirm the need for further research to acquire a better understanding of the processes that underscore individual involvement in online hate in order to inform effective interventions.
\end{abstract}

Keywords Cyberhate $\cdot$ Young people $\cdot$ Victimization $\cdot$ Involvement $\cdot$ School bullying $\cdot$ Overlap

\section{Introduction}

Electronic communication is fully integrated into our daily lives. While it offers an unprecedented means of facilitating communication and freedom of expression worldwide, it can also be misused to convey hate. In an international context of increasing racism, xenophobia, anti-Semitism, and Islamophobia in Europe (FRA, 2013) and the USA (Potok 2011; Hawdon et al. 2015; Lennings et al. 2010), social media that facilitates user-generated content can be viewed as a privileged tool for propaganda and victimization. As such, issues of racism and xenophobia have become more prevalent both in "real life" and on the Internet (Blaya 2019; Chakraborti 2018; Corcoran et al. 2016; EHRC, 2016; Keipi et al. 2016; Williams et al. 2020). According to the Council of Europe Committee of Ministers on "hate speech" (Recommendation No. R (97) 20), online hate speech and the incitement of hatred have a potentially greater impact

Catherine Blaya

Catherine.blaya@hepl.ch

1 University of Teacher Education, Lausanne, Switzerland

2 URMIS, Université Nice Côte d'Azur, Nice, France

3 Swiss Center for Affective Science, Geneva, Switzerland

4 Flinders University, Adelaide, Australia when spread through social media. Indeed, hateful messages can be easily spread through social media Web 2.0 Internetbased applications that make the Internet more interactive and expedite the publication of user-generated content (Kaplan and Haenlein 2010, p. 21).

Furthermore, the Internet offers hatemongers opportunities to recruit sympathizers to their cause and promote a collective identity that may be attractive to the most vulnerable and disfranchised young people in our communities (Perry and Olsson 2009). According to Potok (2011), the number of active hate groups in the US increased by $66 \%$ between 2000 and 2010; today, there are well over 1000 such groups. Whereas Ybarra et al. (2011) found only $3.5 \%$ of children age $10-15$ visited hate sites in 2008 , more recent work by Hawdon et al. (2015) showed that $53 \%$ of respondents were exposed to online hate content, while $16 \%$ were personally targeted. In Europe, the Net Children Go Mobile study reported that the greatest increase in online risk to children was exposure to hateful comments. According to EU Kids Online data, exposure on average increased from $12 \%$ in all countries in 2010 to 23\% in 2013 (Mascheroni and Ólafsson 2014). These findings have been supported by studies in other countries. In the USA, Tynes et al. (2015) showed that from 2010 and 2013 there was an increase in cyberhate victimization, while in France, the International League against Racism and anti-Semitism (LICRA, 2012) and the Commission Nationale Consultative des Droits de l'Homme (National 
Consultative Commission for Human Rights - CNDCH, 2012) also showed a significant increase in racist content online.

In the past decades, research has investigated the association between school bullying and cyberbullying as well as the prevalence of cyberhate and exposure to online hate content (Raskauskas and Stoltz 2007; Riebel et al. 2009; Baldry et al. 2018). However, studies investigating the association between school bullying and cyberhate and more particularly the potential association between being a victim or a perpetrator of school bullying and being involved in cyberhate have been sparse, even though the protagonists of the two types of violence might share common environments.

\section{Cyberhate}

Defined as "an aggressive, intentional act carried out by a group or individual, using electronic forms of contact, repeatedly and over time against a victim who cannot easily defend him or herself" (Smith et al. 2008, p. 376), cyberbullying differs from cyberhate. Foxman and Wolf (2013) liken cyberhate to a virus that spreads like an infectious disease in our societies, affecting our most vulnerable members. Quandt and Festl (2017) have defined cyberhate as "online communication initiated by hate groups with the purpose of attracting new members, building and strengthening group identity, coordinating group action, distributing propagandistic messages and indoctrination, provoking counterreactions as part of propagandistic campaigns, and attacking societal groups and individuals with hateful messages" (p. 1). While this definition focuses on organized groups, individuals can also be involved in cyberhate, either as aggressors or as victims. According to Potok (2011), individuals have become more active than organized groups and this requires further attention.

While cyberhate and cyberbullying both use similar means, intend to harm a person or group of persons and happen in the same context, i.e., online, there are some crucial differences between these two forms of online violence. Hawdon et al. (2015) have indicated that cyberhate is based on prejudice and intolerance. Cyberhate targets more communities than individuals, although it involves individuals or communities that are chosen on specific identified or supposed characteristics. The consequences of cyberhate not only generate individual or community unrest but also contribute to altering social cohesion, democracy, and human rights. Moreover, cyberhate can be a form of online communication from organized hate groups with the purpose of indoctrination and provoking rejection, hatred, and violence against societal groups and individuals. While cyberhate can take the form of cyberbullying in the sense that it can involve repeated and intentional victimization that is based on a power imbalance between the perpetrator and the victim (Baldry et al. 2019), cyberbullying cannot be considered systematically as cyberhate. A prime characteristic of cyberhate is that it targets identity and the community to which individuals belong and rather than occurring repeatedly it can be occasional and triggered by events (Kaakinen et al. 2018).

Most definitions of cyberhate have a common core highlighting the dissemination of hatred through electronic means. However, descriptions of cyberhate differ in terms of their focus (i.e., bigotry, ethnic, or religious). For the purpose of this study, we use the term "cyberhate" to refer to all hateful online forms of expression (text, images, videos, pictures, graphic representations) whose objective is to belittle, humiliate, or ridicule a person or group of persons, in order to generate hatred or rejection of these persons for their genuine or supposed belonging to a specific ethnic or religious background. We shall consider information published both privately and publicly as we investigate exposure to hateful online content produced by individuals as well as organized groups.

\section{Bullying and Cyberbullying, the Evidence of an Overlap}

In the school context, another aspect of inter-personal violence is school bullying. Research evidence shows an overlap between school bullying and cyberbullying (Raskauskas and Stoltz 2007; Riebel et al. 2009). Cyberbullying often roots at school and what happens in cyberspace is often an extension of what happens at school (Wolak et al. 2007; Blaya 2015; Smith et al. 2018). Commonly the same individuals are involved in school bullying and cyberbullying. For example, Hinduja and Patchin (2010) found that students bullied faceto-face (traditional bullying) were 2.5 times more at risk of being cyberbullied than others.

Moreover, there is evidence that victims and perpetrators are in close proximity to each other. Smith et al. (2008) showed that about one third of victims were in the same class group as their aggressors, while Mishna et al. (2010) found that $78 \%$ of victims attended the same school as their aggressors. Similarly, Jones et al. (2013), reported that $60 \%$ of the students were cyberbullied by school mates. Due to the overlap between the two types of victimization, Kowalski and Limber (2013) have suggested that bullying and cyberbullying should be studied together.

Student experiences of aggression in traditional bullying also exacerbate aggressive behaviors in cyberspace ( $\mathrm{Li} 2007$; Smith et al. 2008). With regard to cyberhate, Hawdon et al. (2015) found that being the target of cyberhate was associated with higher odds of becoming a perpetrator of cyberhate.

On their side, Görzig et al. (2019) and also Wachs et al. (2019) show an existing overlap between cyberbullying and cyberhate. According to their findings, the risk of cyberhate victimization and perpetration is increased when individuals are involved in cyberbullying and there is a reciprocal amplification of both behaviors. They argue that based on social 
learning theory as well as on problem behavior theory, cyberhate victims may become cyberhate perpetrators and that this behavior might also be associated with cyberbullying perpetration. Although based on nonrepresentative samples, their studies show the relevance of studying such associations and these findings led us to consider the association and overlap of all three types of aggression, i.e., of traditional bullying, cyberbullying, and cyberhate. A common feature of all three types of aggression is that the behavior involves victims who are targeted by an aggressor who intentionally seeks to harm them. We would anticipate that just as there is a strong association between traditional bullying and cyberbullying that there would also be an association between traditional bullying and cyberhate.

Some research suggests that cyberbullying might be motivated by prior offline victimization and that the Internet, due to the potential safety of anonymity and distance, helps some individuals who would not otherwise perpetrate face-to-face bullying seek revenge online (Smith et al. 2008; Dooley et al. 2009; Hemphill et al. 2012). We therefore expected to find a link between school bullying victimization and cyberhate perpetration as shown in Fig. 1. In a similar vein, we posed the question of whether victims of cyberhate would be motivated to perpetrate traditional bullying at school. If so, we expected to find a positive associated between cyberhate victimization and school bullying perpetration.

Research has clearly established that victims of cyberbullying are in all probability highly likely to be victims of traditional bullying (Kowalski et al. 2012). Subsequently, we posed the question of whether this would also be the case with respect to cyberhate. In other words, are victims of cyberhate likely to be victims of traditional bullying at school and are perpetrators of cyberhate likely to be perpetrators of bullying at school? Since cyberhate is a specific form of cyberbullying, we expected to find a relationship where traditional school bullying victimization would be positively related to cyberhate victimization and likewise, traditional school bullying perpetration would be positively related to cyberhate perpetration.

Shown also in the hypothesized (Fig. 1) model is a correlation between victims and perpetrators. It is known that involvement in bullying can be as a victim, a bully, or as a bullyvictim, i.e., young people who are victims of bullying, but who also bully others (Haynie et al. 2001). In a similar vein, and in accordance with Hawdon et al.'s (2015) findings, we anticipated an association between cyberhate victims and perpetrators.

In this study, we specifically focused on questions regarding participants' school bullying experiences, which included victimization and perpetration, as well as cyberhate victimization and perpetration in order to test the proposed model. In light of our expectations, we proposed the model shown in Fig. 1 to represent the relationships between traditional bullying victimization, cyberhate victimization, traditional bullying perpetration, and cyberhate perpetration. As shown in the model, we expected to find positive relationships between

- School bullying victimization and cyberhate victimization

- School bullying victimization and cyberhate perpetration

- School bullying victimization and school bullying perpetration

- Cyberhate victimization and school bullying perpetration

- Cyberhate victimization and cyberhate perpetration

- School bullying perpetration and cyberhate perpetration

Currently, the scant research on cyberhate among adolescents has left a gap in the literature and little is known of the prevalence of cyberhate victimization and perpetration. A further aim of the study was how often young people in France reported cyberhate.

Fig. 1 Hypothesized model of the association of school bullying and cyberhate

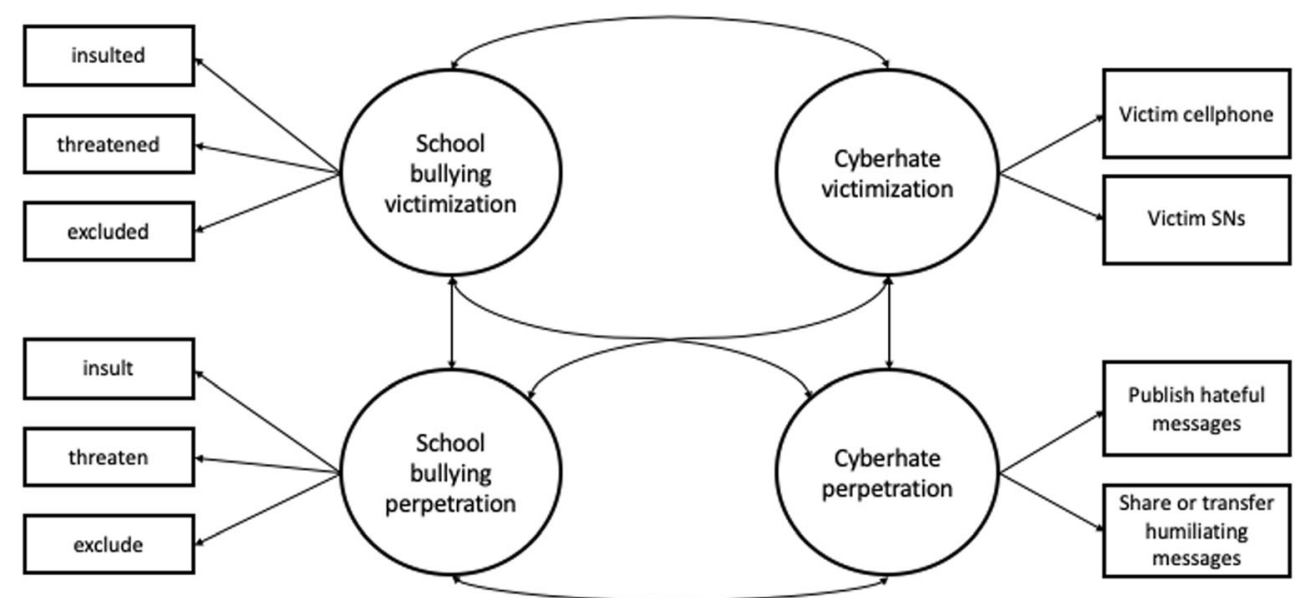




\section{Method}

\section{Participants and Procedure}

Secondary school students enrolled in 6th through 12th grades $(N=1900)$ aged 12-20, from 16 schools in France, completed an online questionnaire. State schools were selected randomly from a list of schools produced by the Education Board and were contacted. It was thus a convenience sample as 16 from the selected 45 chose to participate. All students from one class, which was randomly selected by the research team in each year group (grade), completed the questionnaire. The student population of these schools was diverse, located in areas that ranged from upper-class downtown Paris to remote rural areas in the South West of France. Schools were invited to participate, and parental consent was sought for students under 18 years of age. Assent from the participating students was also requested.

All data were collected anonymously during spring 2016. In each school, questionnaires were administered online under the supervision of a research assistant in the school's computer (IT) room. To ensure confidentially, trust and accuracy of students' responses, no school staff was present during data collection, which took no longer than $45 \mathrm{~min}$.

\section{Measures}

The questionnaire was based on the EU Kids Online survey (Livingstone et al. 2011) and commonly used by other researchers (e.g., Blaya and Audrin 2019; Blaya and Gatti 2010). As previously shown by Blaya and Audrin (2019), this questionnaire yields good reliability indices $(\alpha=.95, \omega=.96)$. The questionnaire comprised several questions about the socio-demographic characteristics of respondents (gender and age) and their families, their digital practices (ICT use), their experiences of bullying in schools, and their satisfaction with life. Participants were also asked information regarding their religion and attitudes toward violence, their trust in institutions, the characteristics of their peer group, and their attitudes toward racism. To ensure parsimony and minimize the cognitive burden on participants, questions in each section were kept to a minimum.

\section{School Bullying Victimization}

School bullying victimization was measured with three items ( $\alpha=.66, \omega=.68$ ), which assessed how many times during the past 6 months participants were (1) insulted, or made fun of; (2) threatened; or (3) excluded, by other students of their school. Participants were asked to answer on a scale ranging from 1 (never) to 5 (5 times and more).

\section{Cyberhate Victimization}

Cyberhate victimization was measured by two items ( $\alpha=.67$, $\omega=.70)$. Item one asked participants if during the past 6 months, they had been the target of hateful or humiliating messages, comments, or images on their cell phone. Item two asked participants if during the last 6 months they had been the target of hateful or humiliating messages, comments, or images on social media. For both items, participants were asked to answer on a scale ranging from 1 (never) to 5 (5 times and more).

\section{School Bullying Perpetration}

School bullying perpetration was measured with three items ( $\alpha=.61, \omega=.63$ ). Similar to the offline victimization dimension, participants were asked how many times they (1) insulted or made fun of others, (2) threatened others, or (3) excluded other students. They were asked to answer on a scale ranging from 1 (never) to 5 (5 times and more).

\section{Cyberhate Perpetration}

Cyberhate perpetration was measured by two items $(\alpha=.68$, $\omega=.69$ ). Participants were asked if they had (1) published or (2) shared or transferred humiliating or hateful messages, images, or comments toward one specific person or a group of persons on the Internet. Participants were asked to answer on a scale ranging from 1 (never) to 5 (5 times and more).

\section{Data Analyses}

Analyses were performed using R and Mplus version 7.4. Due to the non-normality of our data, we computed robust maximum likelihood estimates. We kept at least two items for each latent variable, as recommended by Kenny (http:// davidakenny.net $/ \mathrm{cm} /$ identify.htm). Items were kept if their factor loadings (as computed in the hypothesized model depicted in Fig. 1 were equal or higher than .3 and if their $R^{2}$ was equal or higher than .3. To assess the model's goodness-of-fit, we relied on indices having different measurement properties, as recommended by $\mathrm{Hu}$ and Bentler (1998). Thus, we used the root mean-square error of approximation (RMSEA), the comparative fit indices (CFI), and the SRMR statistics. Browne and Cudeck (1992) suggest that models with RMSEA below .05 are indicative of good fit, and that values up to .08 reflect reasonable errors of approximation. The CFI statistic (McDonald and Marsh 1990) reflects the "distance" of the model from the perfect fit. It is generally acknowledged that a value greater than .9 reflects an acceptable distance to the perfect fit. We also report the SRMR statistics, which represent an averaged distance between the hypothesized model and the real model ( $\mathrm{Hu}$ and 
Bentler 1998). This statistics ranges from 0 to 1 and is considered "good" if it is small (around .05 or less). Finally, we report the $\mathrm{chi}^{2} / \mathrm{df}$ ratio, whose value is considered acceptable if it is of 5 or less (Statistics Solutions 2020).

\section{Results}

\section{Participants}

The age of the 1900 participants ranged between 11 and 20 years (age mean $=14.631, \mathrm{SD}=2.053$ ), $50.25 \%$ were females, $49.75 \%$ were males). As shown in Table 1 , nearly two thirds $(64.4 \%)$ of the participants indicated that they had been insulted by someone during the past 6 months either online or face-to-face, while just over half $(52.3 \%)$ reported that they had insulted someone else either online or face-to-face. Furthermore, one out of ten $(10.5 \%)$ respondents reported cyberhate victimization while $5.2 \%$ acknowledged cyberhate perpetration. Findings show that the percentages of young people involved as victims or perpetrators were much higher offline (traditional) than online (cyber).

A good fit with the data was found for the hypothesized model, as shown in Fig. 2 (RMSEA $=.046, \mathrm{CFI}=.948$, and $\left.\mathrm{SRMR}=.034, \mathrm{chi}^{2} / \mathrm{df}=1.645\right)$. The factor loadings for latent variable items are shown in Table 2. The analysis indicated that items have strong loadings on their respective latent factors, while (as expected) moderate to strong links between the four latent factors were found. (see Fig. 2 and Table 3).

Regarding the links between factors (see Table 3 ), analyses found that school bullying perpetration and cyberhate perpetration were related $(r=.295, p=.001,95 \% \mathrm{CI}=[.144$; $.447]$ ), suggesting that in schools where students insult, threaten, or make fun of others in everyday life, students may also perpetrate hate messages against others online. The link between online and offline behaviors was significant for victimization $(r=.469, p=.001,95 \% \mathrm{CI}=[.391 ; .547)$, revealing that the more likely students are to be bullied at school, the more likely they are to face humiliating hate messages online. Interestingly, results revealed a strong relationship between school bullying perpetration and victimization $(r=.436, p=.001,95 \% \mathrm{CI}=[.345 ; .527])$, but a weaker relationship between cyberhate victimization and cyberhate perpetration $(r=.341, p=.001,95 \% \mathrm{CI}=[.196 ; .485])$.

Finally, we found a moderate relationship between school bullying victimization and cyberhate perpetration $(r=.185$, $95 \% \mathrm{CI}=[.086 ; .283])$, as well as a moderate relationship between cyberhate victimization and school bullying perpetration $(r=.192, p=.001,95 \% \mathrm{CI}=[.085 ; .299])$.

\section{Discussion}

In our study, we sought to investigate the association of offline victimization and perpetration of bullying and cyberhate since this has never been closely investigated. Our findings have important implications for both research and practice. One out of ten respondents reported cyberhate victimization while $5 \%$ of them acknowledged perpetration. Within the limitations of our sample, this provides evidence that hatred is part of the online experience for many young people. These children are potentially fragilized in their identity, self-esteem (Tynes 2006), and their social life (Awan and Zempi 2016). In a population of five and a half million adolescents, 5\% equates to 275,000 young people, so there is a genuine need to take the issue seriously.

Table 1 Proportion of participants facing or using online and offline violence for each experience

\begin{tabular}{|c|c|c|c|c|c|c|}
\hline & Never in the last 6 months & Boys & Girls & At least once in the last 6 months & Boys & Girls \\
\hline School bullying victim & $58.4 \%$ & & & $41.6 \%$ & & \\
\hline Insulted by someone & $640(35.6 \%)$ & 377 & 263 & $1173(64.4 \%)$ & 525 & 649 \\
\hline Threatened by someone & $1261(69.5 \%)$ & 627 & 634 & $554(30.5 \%)$ & 271 & 283 \\
\hline Excluded by others & $1271(70.1 \%)$ & 681 & 590 & $541(29.9 \%)$ & 218 & 323 \\
\hline Cyberhate victim & $89.5 \%$ & & & $10.5 \%$ & & \\
\hline Targeted on cell phone & $1597(88.6 \%)$ & 819 & 778 & $208(11.4 \%)$ & 76 & 132 \\
\hline Targeted on social media & $1625(90.4 \%)$ & 830 & 795 & $172(9.6 \%)$ & 61 & 111 \\
\hline School bullying perpetrator & $65.5 \%$ & & & $34.3 \%$ & & \\
\hline Insulted someone & $867(47.7 \%)$ & 413 & 454 & $950(52.3 \%)$ & 588 & 461 \\
\hline Threatened someone & $1501(82.9 \%)$ & 705 & 800 & $307(17.1 \%)$ & 195 & 112 \\
\hline Rejected someone & $1201(66.3 \%)$ & 589 & 603 & $618(33.7 \%)$ & 309 & 309 \\
\hline Cyberhate perpetrator & $94.8 \%$ & & & $5.2 \%$ & & \\
\hline Published material online & $1712(94.7 \%)$ & 833 & 879 & $96(5.3 \%)$ & 62 & 34 \\
\hline Shared/transferred material online & $1716(94.9 \%)$ & 850 & 866 & $90(5.1 \%)$ & 48 & 42 \\
\hline
\end{tabular}


Table 2 Factor loadings for the online and offline victimization and online and offline aggression latent factors from RML estimations, $p<.001 * * *$

\begin{tabular}{|c|c|c|c|c|c|c|}
\hline & \multirow[t]{2}{*}{ Estimate } & \multirow[t]{2}{*}{ SD } & \multirow[t]{2}{*}{ Standardized estimate } & \multirow[t]{2}{*}{$p$ value } & \multicolumn{2}{|l|}{$95 \% \mathrm{CI}$} \\
\hline & & & & & Lower & Higher \\
\hline \multicolumn{7}{|l|}{ Cyberhate victimization } \\
\hline Victim hateful messages (victim cellphone) & 2.353 & .216 & .814 & .001 & .729 & .899 \\
\hline Victim hateful messages (victim social network) & 2.071 & .202 & .789 & .001 & .708 & .870 \\
\hline \multicolumn{7}{|l|}{ Cyberhate perpetration } \\
\hline Publish hateful messages & 1.000 & .000 & .810 & .001 & 686 & .934 \\
\hline Share/transfer hateful messages & 0.803 & .109 & 603 & .001 & .474 & .731 \\
\hline \multicolumn{7}{|l|}{ School bullying victimization } \\
\hline Being insulted & 1.000 & .000 & .517 & .001 & .452 & .582 \\
\hline Being threatened & 1.743 & .164 & .662 & .001 & .597 & .726 \\
\hline Being excluded & 1.089 & .105 & .688 & .001 & .625 & .752 \\
\hline \multicolumn{7}{|l|}{ School bullying perpetration } \\
\hline Threatened someone & 2.668 & .376 & .725 & .001 & .616 & .833 \\
\hline Excluded someone & 1.548 & .206 & .651 & .001 & .548 & .757 \\
\hline
\end{tabular}

The structural equation modeling analysis found an association between victimization and perpetration for both offline and online behavior. It seems that offline perpetrations increase as either offline or online victimization increases. Offline victimization was also correlated with cyberhate victimization. These results align with propositions of an overlap among perpetrators and victims (Jennings et al. 2012; Hawdon et al. 2015). This can partly be explained by the fact that victims and offenders often share similar environments both online and offline (Hinduja and Patchin 2010). Our findings support the old adage that "violence breeds violence." It appears that opportunities are taken by young people to target others whether that is in traditional face-to-face approaches or through anonymous means online.
Newman and Newman (2012) have described the importance of adolescent friendship group and cliques, so our findings could be interpreted through the lens of Socio-Identity Theory (SIT). This theory posits that social groups form on an insider/outsider basis and belonging to one group is an important part of social identity. This can explain both victimization and perpetration, as different groups thrive on conflict and prejudice. The aim of outgroup bias is to value one's own group to the detriment of the other group (Tajfel and Turner 1979). This could explain the association of victimization and perpetration, particularly through anonymous electronic means, as young people invest in maintaining the cohesion of their own social group. Young people outside the social group, with no group to defend them, would be the most vulnerable. Indeed, research by Oksanen et al. (2014) and

Table 3 Correlation between latent factors in the hypothesized model

\begin{tabular}{|c|c|c|c|c|}
\hline & \multirow[t]{2}{*}{ Correlation $(r)$} & \multirow[t]{2}{*}{$p$ value } & \multicolumn{2}{|c|}{$95 \% \mathrm{CI}$} \\
\hline & & & Lower & Upper \\
\hline Cyberhate victimization and cyberhate perpetration & & & .196 & .485 \\
\hline & .341 & .001 & & \\
\hline School bullying victimization and school bullying perpetration & .436 & .001 & .345 & .527 \\
\hline Cyberhate victimization and school bullying perpetration & .192 & .001 & .085 & .299 \\
\hline Cyberhate perpetration and school bullying victimization & .185 & .001 & .086 & .283 \\
\hline Cyberhate victimization and school bullying victimization & .469 & .001 & .391 & .547 \\
\hline Cyberhate perpetration and school bullying perpetration & .295 & .001 & .144 & .447 \\
\hline
\end{tabular}


Fig. 2 Hypothesized model of school bullying and cyberhate

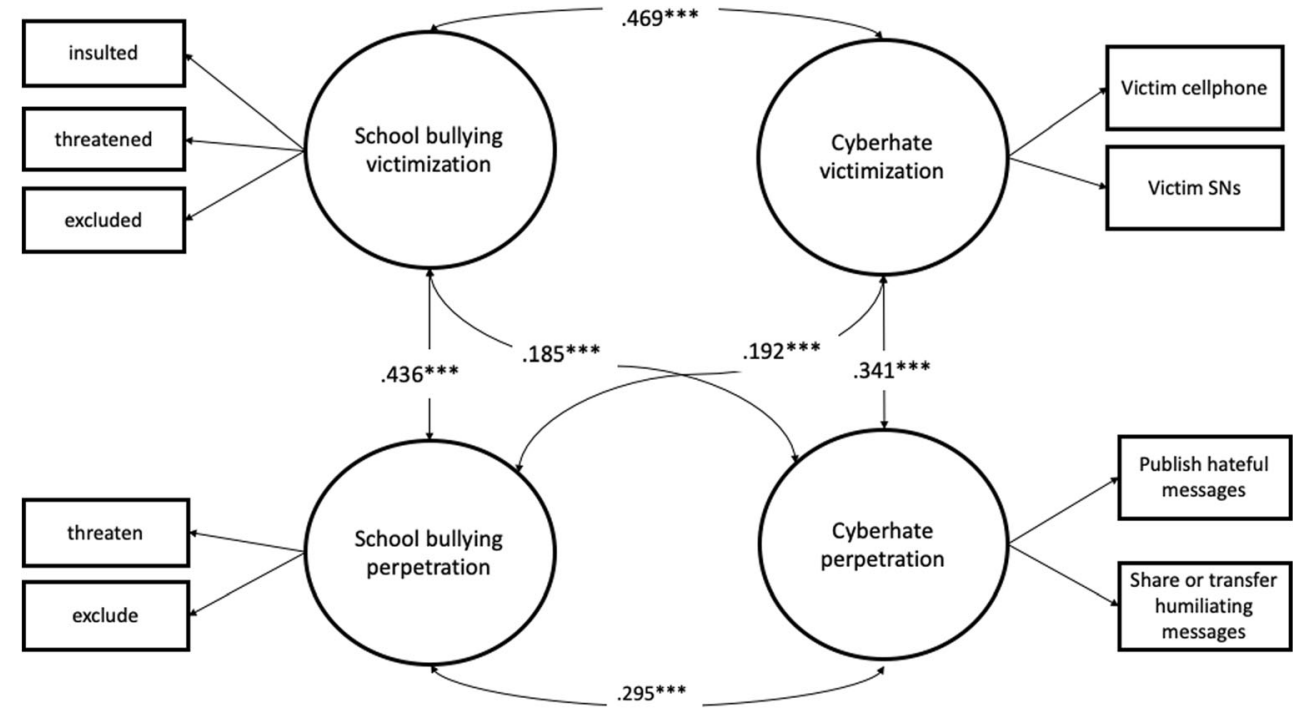

Tynes (2006) has shown that victims of cyberhate tend to withdraw socially and not to aggress in return.

Given the overlap between bullying and cyberhate, existing intervention programs against school bullying should also tackle cyberhate. Despite developments in interventions against school bullying, cyberhate is one of the issues that has increased the most in the experiences of young people compared with other forms of identity-based cyberbullying (Hawdon et al. 2015). This leads us to stress the need for stronger input from educational institutions in the constructive role they can take to raise awareness and concern among young people toward human rights, diversity, and tolerance as well as IT literacy and to empower young people to reduce online risk taking and cyberhate. This survey has implications for educational practice. While we are facing increasing division on religion, economic, and cultural criteria, we need to get a clearer understanding of our diversities if we wish to smooth the devastating effects of discrimination, racism, xenophobia, Islamophobia, and anti-Semitism as well as antiWest culture, to achieve a positive cohesion of society and youth.

Although the current study utilized a large and diverse sample of youth, limitations must be noted. Findings cannot be generalized due to the non-representative sample that is based on individuals who agreed to complete the questionnaire and schools who volunteered to participate. Moreover, our data were cross-sectional and collected at one point in time, we cannot therefore draw any conclusions regarding the causality between being a victim or a perpetrator. Future studies should adopt longitudinal designs in order to assess this point. Questionnaires are self-reported, and answers are potentially biased like any survey of this type. Potential biases are recall and social desirability. However, to limit recall bias, questions were about the 12 months previous to the survey. We sought to minimize social desirability, by ensuring that the questionnaires were totally anonymous and completed in exam like conditions. Students were isolated to a single table, under the supervision of two researchers and had no opportunity to communicate with others.

The items selected to measure both traditional bullying and cyberhate provide a limited view of what cyberhate could look like and it would be prudent to further investigate more forms of expression of both types of negative behaviors. Finally, our data were cross-sectional and collected at one point in time, we cannot therefore draw any conclusions regarding the causality between being a victim or a perpetrator. Future studies should adopt longitudinal designs in order to assess this point.

Acknowledgments Data were collected with the help of Jean-François Bruneaud (University of Bordeaux), Aurélie Dumond (University Nice Sophia Antipolis), and Naima Anka Idrissi (University Paris VIII).

Funding Open access funding provided by The University of Teacher Education, State of Vaud (HEP Vaud). This work was supported by the Centre National de la Recherche Scientifique (call for research projects "attentats-recherche," 2016).

\section{Compliance with Ethical Standards}

Conflict of Interest The authors declare that they have no conflict of interest.

Research Involving Human Participants and/or Animals The survey was approved by the ethics committee of the Universite Nice Sophia Antipolis and fulfills the requirements from the CNIL and CNRS.

Informed Consent Participants and their legal representant gave their informed consent to their participation to the research.

Open Access This article is licensed under a Creative Commons Attribution 4.0 International License, which permits use, sharing, adaptation, distribution and reproduction in any medium or format, as long as you give appropriate credit to the original author(s) and the source, provide a link to the Creative Commons licence, and indicate if changes were 
made. The images or other third party material in this article are included in the article's Creative Commons licence, unless indicated otherwise in a credit line to the material. If material is not included in the article's Creative Commons licence and your intended use is not permitted by statutory regulation or exceeds the permitted use, you will need to obtain permission directly from the copyright holder. To view a copy of this licence, visit http://creativecommons.org/licenses/by/4.0/.

\section{References}

Awan, I., \& Zempi, I. (2016). The affinity between online and offline anti-Muslim hate crime: Dynamics and impacts. Aggression and Violent Behavior, 27, 1-8. https://doi.org/10.1016/j.avb.2016.02. 001.

Baldry, A. C., Sorrentino, A., \& Farrington, D. P. (2019). Cyberbullying and cybervictimization versus parental supervision, monitoring and control of adolescents' online activities. Children and Youth Services Review, 96, 302-307.

Baldry, A., Blaya, C., Farrington D. (Eds.). (2018). International perspectives on cyberbullying. Palgrave studies in cybercrime and cybersecurity. London: Palgrave MacMillan.

Blaya, C. (2019). Cyberhaine, les jeunes et la violence sur Internet. [Cyberhate, young people and violence on the Internet]. Editions Nouveau Monde.

Blaya, C. (2015). In Murat, F. et C. Simonis-Sueur. L'école à l'ère du 2.0 : climat scolaire et cyberviolence. Climat scolaire et bien -être. Education et Formations $n^{\circ}$ 88-89(32), 29-39.

Blaya, C., \& Audrin, C. (2019). Toward an understanding of the characteristics of secondary school cyberhate perpetrators. Frontiers in Education, 4. https://doi.org/10.3389/feduc.2019.00046.

Blaya, C., \& Gatti, U. (2010). Deviant youth groups in Italy and France: Prevalence and characteristics. European Journal on Criminal Policy and Research, 16(2), 127-144.

Browne, M. W., \& Cudeck, R. (1992). Alternative ways of assessing model fit. Sociological Methods \& Research, 21(2), 230-258. https://doi.org/10.1177/0049124192021002005.

Chakraborti, N. (2018). Responding to hate crime: Escalating problems, continued failings. Criminology \& Criminal Justice, 18(4), 387 404

CNDCH (2013). La lutte contre le racisme, l'antisémistimes et la xénophobie. Paris: $\mathrm{CNDCH}$.

Corcoran, H., Lader, D., \& Smith, K. (2016). Hate crime, England and Wales. Statistical Bulletin, 5, 15.

Dooley, J. J., Pyzalski, J., \& Cross, D. (2009). Cyberbullying versus face to-face bullying. Journal of Psychology, 217(4), 182-188.

Equality and Human Rights Commission. 2016. Healing a Divided Britain. London: EHRC.

Foxman, A. H., \& Wolf, C. (2013). Viral hate: Containing its spread on the internet. New York: Macmillan.

FRA (2013). LGBT persons' experiences of discrimination and hate crime in the EU and Croatia. Vienna: FRA, retrieved from http:// fra.europa.eu/en/publication/2013/lgbt-persons-experiencesdiscrimination-and-hate-crime-eu-and-croatia

Görzig, A., Wachs, S., \& Wright, M. (2019) Cyberhate and cyberbullying: joint propensity and reciprocal amplification. In: International Society of Political Psychology, 12-15, Lisbon, Portugal. (Unpublished).

Hawdon, J., Oksanen, A., \& Räsänen, P. (2015). Online extremism and online hate: Exposure among adolescents and young adults in four nations. Nordicom Information: Medie-och kommunikationsforskning $i$ Norden, 37(3-4), 29-37.
Haynie, D. L., Nansel, T., Eitel, P., Crump, A. D., Saylor, K., Yu, K., \& Simons-Morton, B. (2001). Bullies, victims, and bully/victims: Distinct groups of at-risk youth. The Journal of Early Adolescence, 21(1), 29-49.

Hemphill, S. A., Kotevski, A., Tollit, M., Smith, R., Herrenkohl, T. I., Toumbourou, J. W., \& Catalano, R. F. (2012). Longitudinal predictors of cyber and traditional bullying perpetration in Australian secondary school students. Journal of Adolescent Health, 51(1), 59-65.

Hinduja, S., \& Patchin, J. W. (2010). Bullying, cyberbullying, and suicide. Archives of Suicide Research, 14(3), 206-221.

Hu, L., \& Bentler, P. M. (1998). Fit indices in covariance structure modeling: Sensitivity to underparameterized model misspecification. Psychological Methods, 3(4), 424-453.

Jennings, W. G., Piquero, A. R., \& Reingle, J. M. (2012). On the overlap between victimization and offending: A review of the literature. Aggression and Violent Behavior, 17(1), 16-26. https://doi.org/10. 1016/j.avb.2011.09.003.

Jones, L. M., Mitchell, K. J., \& Finkelhor, D. (2013). Online harassment in context: Trends from three youth internet safety surveys (2000, 2005, 2010). Psychology of Violence, 3(1), 53-69.

Kaakinen, M., Oksanen, A., \& Räsänen, P. (2018). Did the risk of exposure to online hate increase after the November 2015 Paris attacks? A group relations approach. Computers in Human Behavior, 78, 9097.

Kaplan, A. M., \& Haenlein, M. (2010). Users of the world, unite! The challenges and opportunities of social media. Business Horizons, 53(1), 59-68.

Keipi, T., Näsi, M., Oksanen, A., \& Räsänen, P. (2016). Online hate and harmful content: Cross-national perspectives (p. 154). Taylor \& Francis.

Kowalski, R. M., \& Limber, S. P. (2013). Psychological, physical, and academic correlates of cyberbullying and traditional bullying. Journal of Adolescent Health, 53(1), S13-S20.

Kowalski, R. M., Morgan, C. A., \& Limber, S. P. (2012). Traditional bullying as a potential warning sign of cyberbullying. School Psychology International, 33(5), 505-519. https://doi.org/10.1177/ 0143034312445244

Lennings, C. J., Amon, K. L., Brummert, H., \& Lennings, N. J. (2010). Grooming for terror: The Internet and young people. Psychiatry, Psychology and Law, 17(3), 424-437. https://doi.org/10.1080/ 13218710903566979.

Li, Q. (2007). Bullying in the new playground: Research into cyberbullying and cyber victimisation. Australasian Journal of Educational Technology, 23(4).

LICRA (2012). Contribution de la Ligue Internationale Contre le Racisme et l'Antisémitisme. CNDCH. Paris: Rapport d'Activité.

Livingstone S., Haddon L., Görzig A., \& Olafsson K (2011). Risks and safety on the internet: The perspective of European children. Full findings. http://eprints.lse.ac.uk/33731/

Mascheroni, G., \& Ólafsson, K. (2014). Net Children Go Mobile: Risks and opportunities (2nd ed.). Milano: Educatt.

McDonald, R. P., \& Marsh, H. W. (1990). Choosing a multivariate model: Noncentrality and goodness of fit. Psychological Bulletin, 107(2), 247-255.

Mishna, F., Cook, C., Gadalla, T., Daciuk, J., \& Solomon, S. (2010). Cyber bullying behaviors among middle and high school students. The American Journal of Orthopsychiatry, 80(3), 362-374.

Newman, B. M., \& Newman, P. R. (2012). Development through life: A psychosocial approach. Belmont: Wadsworth, Cengage Learning.

Oksanen, A., Hawdon, J., Hokeri, E. Näsi, M., Räsänen, P. (2014). Exposure to online hate among young social media users, in M. N. Warehime (ed.) Soul of society a focus on the lives of children and youth (sociological studies of children and youth, volume 18). Emerald Group Publishing Limited, pp. 253-273.

Perry, B., \& Olsson, P. (2009). Cyberhate: The globalization of hate. Information \& Communications Technology Law, 18(2), 185-199. 
Potok, M. (2011). The year in hate and extremism, 2010. Intelligence Report, 141. Montgomery: Southern Poverty Law Center.

Quandt, T. and Festl, R. (2017). Cyberhate. In The international encyclopedia of media effects (Eds P. Rössler, C. A. Hoffner and L. Zoonen). https://doi.org/10.1002/9781118783764.wbieme0215.

Raskauskas, J., \& Stoltz, A. D. (2007). Involvement in traditional and electronic bullying among adolescents. Developmental Psychology, 43(3), 564-575.

Riebel, J., Jäger, R. S., \& Fischer, U. C. (2009). Cyberbullying in Germany-an exploration of prevalence, overlapping with real life bullying and coping strategies. Psychology Science Quarterly, 51, 298-314 10.1.1.599.3516\&rep=rep1\&type=pdf. Accessed 15 July 2020.

Smith, P. K., Sundaram, S., Spears, B. A., Blaya, C., Schäfer, M., \& Sandhu, D. (Eds.). (2018). Bullying, cyberbullying and student well-being in schools. Comparing European, Australian and Indian perspectives. Cambridge: Cambridge University Press.

Smith, P. K., Mahdavi, J., Carvalho, M., Fisher, S., Russell, S., \& Tippett, N. (2008). Cyberbullying: Its nature and impact in secondary school pupils. Journal of Child Psychology \& Psychiatry, 49(4), 376-385.

Statistics Solutions (2020). The chi-square test in structural equation modeling. https://www.statisticssolutions.com/the-chi-square-testin-structural-equation-modeling/. Accessed 15 July 2020.

Tajfel, H., \& Turner, J. C. (1979). An integrative theory of intergroup conflict. In W. G. Austin \& S. Worchel (Eds.), The social psychology of intergroup relations (pp. 33-47). Monterey: Brooks-Cole.

Tynes, B. (2006). Children, adolescents, and the culture of online hate. In N. E. Dowd, D. G. Singer, \& R. F. Wilson (Eds.), Handbook of children, culture, and violence (pp. 267-289). Thousand Oaks: Sage.

Tynes, B., Del Toro, J., \& Lozada, T. (2015). An unwelcomed digital visitor in the classroom: The longitudinal impact of online racial discrimination on academic motivation. School Psychology Review, 44(4), 407-424. https://doi.org/10.17105/SPR-15-0095.1.

Wachs, S., Wright, M. F., \& Vazsonyi, A. T. (2019). Understanding the overlap between cyberbullying and cyberhate perpetration: Moderating effects of toxic online disinhibition. Criminal Behaviour and Mental Health, 29(3), 179-188.

Williams, M. L., Burnap, P., Javed, A., Liu, H., \& Ozalp, S. (2020). Hate in the machine: Anti-Black and anti-Muslim social media posts as predictors of offline racially and religiously aggravated crime. The British Journal of Criminology, 60(1), 93-117. https://doi.org/10. 1093/bjc/azz049.

Wolak, J., Mitchell, K. J., \& Finkelhor, D. (2007). Does online harassment constitute bullying? An exploration of online harassment by known peers and online-only contacts. Journal of Adolescent Health, 41(6), S51-S58.

Ybarra, M. L., Mitchell, K. J., \& Korchmaros, J. D. (2011). National trends in exposure to and experiences of violence on the internet among children. Pediatrics, 128(6), 1376-1386. https://doi.org/10. 1542/peds.2011-0118.

Publisher's Note Springer Nature remains neutral with regard to jurisdictional claims in published maps and institutional affiliations.

Catherine Blaya is Professor in Education Sciences at the faculty for teachers education at the University Côte d'Azur (Nice, France). She is Dean of the faculty and is member of the Research Unit on Migrations and Society (UMR CNRS 8245-IRD 205) specialized in the study of migrations and interethnic relations. She is part of the EU Kids Online research group and leads research in France. She has been dedicating her academic career to researching issues that might affect the young people's lives such as dropping out of school, school climate, cyberbullying, and cyberhate.

Catherine Audrin is a scientific collaborator at the University of Teacher Education (Lausanne, Switzerland). Her work particularly focuses on the importance of emotions in students and learners, and on the importance of well-being in educational contexts.

Grace Skrzypiec is a senior lecturer in the College of Education, Psychology and Social Work and the (Co)Director of the Student Wellbeing and Prevention of Violence (SWAPv) research centre. Grace was the recipient of the 2014 Vice-Chancellor's Award for Early Career Researchers in recognition of outstanding contributions to excellence in research. From 2018-2020 she was Co-President of the International Observatory on School Climate and Violence Prevention. 